\title{
Addressing Student Resilience in Post-Baccalaureate Programs: A Review of the Literature
}

\author{
Mitzi S. Brammer, Ph.D. \\ Saint Louis University \\ 3750 Lindell Blvd. \\ St. Louis, MO 63108 \\ United States
}

\begin{abstract}
The purpose of this review is to capture the scope of literature with regard to the current state of supports addressing student resilience. More specifically, this researcher is interested in those structures and interventions that are in place for post-baccalaureate students in higher education plans of study. In its infancy, research and intervention addressing this topic occurred at the K-12 level of education and later moved into baccalaureate programs of study for the most part. In addition, this research investigates the literature in order to explore the desired state in terms of student resilience. A deeper understanding of these two factors will drive future research in terms of the development and evaluation of appropriate interventions to address post-baccalaureate student resilience in higher education.
\end{abstract}

Keywords: Resilience, Graduate Education, Post-Baccalaureate, Literature Review

\section{Introduction}

This literature review will address different facets of student resilience to explore the current state of this phenomenon in terms of post-baccalaureate study. In addition, this researcher will posit the direction in which research should proceed to more satisfactorily address student resilience in higher education, specifically in post-baccalaureate programs. The theoretical framework represented in Figure 1 has been proposed and used in this paper as the method to conduct and guide the investigation of student resilience and post-baccalaureate education through an in-depth literature review. The first section describes how the definition of student resilience is perceived by different researchers. This includes those factors that influence resilience as well as bases for lack of resilience in students who are in higher education. Next, theoretical underpinnings for resilience models are shared. Finally, different ways that student resilience has been addressed in the past at the university/college level are presented.

Figure 1: Theoretical Framework for Literature Review

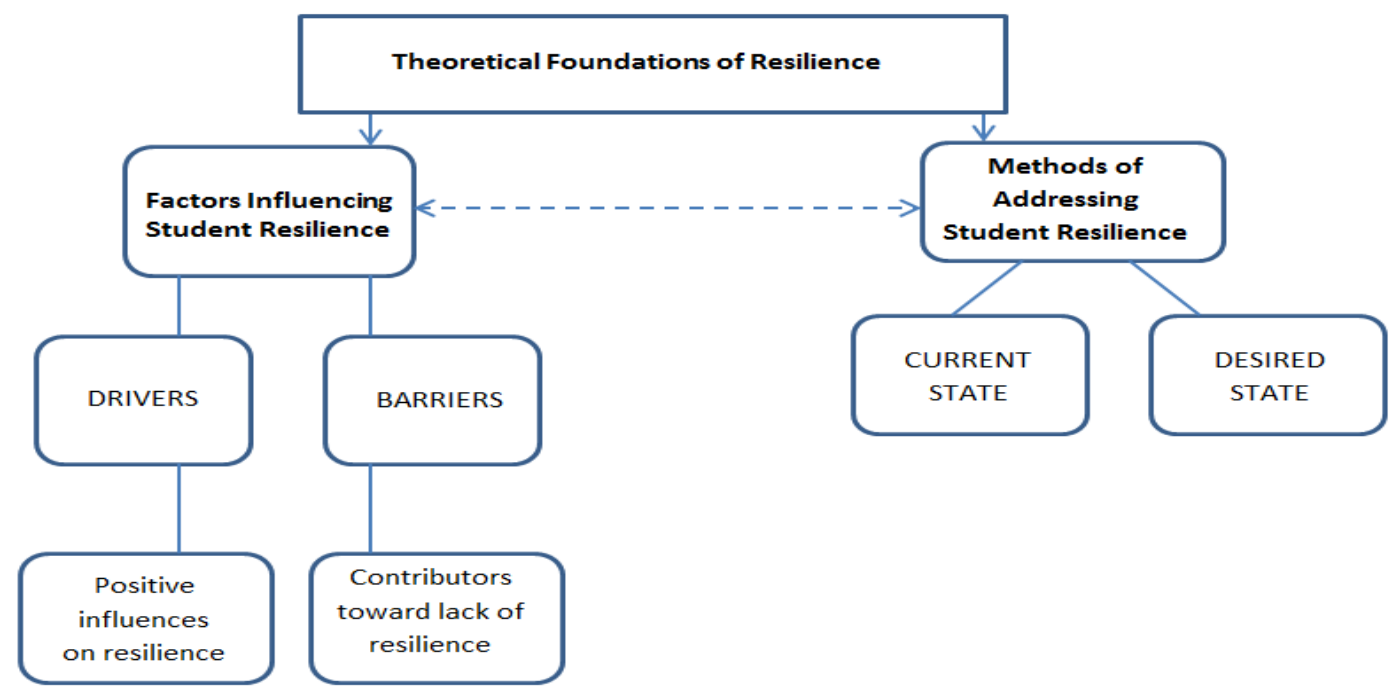

The study of resilience began decades ago as researchers investigated this phenomenon in terms of how individuals react to traumatic situations or circumstances such as war or disasters. Over the years, this area of research has evolved to other arenas such as the work force and education. In the early 1990s, before social media and technology grew to the ubiquitous presence they have today, Kegan (1994) revealed that there was no mental paradigm or way of thinking to be able to handle modern life and its stressors. 
He believed that in order to be effective human beings in the $21^{\text {st }}$ century, we needed a new way of structuring our world. He believed that higher education was the venue for the teaching and development of a new mind-set. After all, many students are preparing to go into health and helping professions that include similar stressors to pre-professional students. Moreover, students who are in their school to work transition which is defined as that period between the final semesters of college and the individual's first full-time job tend to be confronted with a variety of stressors (Kim \& Lee, 2018). These include but are not limited to time pressures, workload, multiple professional roles, emotional/mental health issues such as anxiety or depression, and unhealthy relationship behaviors(Beiter, Nash, McCrady, et al., 2015; First, First, \& Houston, 2018; McCann, Beddoe, McCormick, et al., 2013). Transfer students also experienced similar stressors, especially anxiety and depression (Beiter, Nash, McCrady, et al., 2015).

Relative to education, researchers have largely been interested in investigating student resilience in grades kindergarten through 12. In their meta-analysis of resilience program studies in higher education, Leppin et al. (2014) found only a few studies that included university-level students. Those studies that have explored student resilience in higher education have primarily observed facets of resilience in undergraduate students rather than graduate students. Brzycki and Brzycki's (2016) work on student success in higher education outlines the most effective ways to engage students at the college/university level. Again, this is more geared toward undergraduate higher education. However, teaching students about well-being and success and providing opportunities across different campus environments should not be limited to just undergraduates. Winfield (1994) discusses the changes a student goes through in each step of schooling. These are known as critical transition points, or CTPs. It is important that resilience research look at different points of transition because this is when students' vulnerability is high, including transitioning from undergraduate to graduate education. Given the dearth of research on graduate studies and student resilience, it is as if there is not a realization that graduate students also experience stressors that could lead to resilience issues. Students who are in graduate school, rigorous programs of study by nature, need to be able to function well in the academic environment by adapting to challenging situations in and out of the classroom. Doing so helps to maintain a high quality of life (Leppin et al., 2014).Moreover, Avey, Luthans, and Jensen (2009) and First, First, and Houston (2018) indicate that implementing interventions in higher education that promote the coping skills necessary for resilience not only address but also prevent increased stress. Students are more open to new experiences; they are more flexible when faced with changing demands; and they possess more emotional stability when facing challenges. This aligns with Kegan's (1994) assertion for a necessary means to address those factors that impact student resilience in higher education.

\section{How is Resilience Defined?}

Resilience is multi-faceted. It is a complex construct in that it is made up of many parts overlapping and intersecting. Aydogdu, Celik, and Eksi (2017); Di Fabio and Saklofske (2018); and Morales (2008) define resilience as both an outcome as well as a process (i.e., the interaction between risk and protective factors, areas of vulnerability, and compensatory strategies). Carver (1998); Prihadi, Cheow, Yong, and Sundrasagran (2018); de Oliveria, Machado, and Aranha (2017); Luthar (2006); Smith (2018); Windle (2011); Winfield (1994); and Eells (2017) share similar perspectives on the definition of resilience. That is, there are always the following components present: 1) the individual; 2) stressor(s) such as some sort of adverse or difficult condition; and 3) persevering despite the difficulty or challenging situation.

According to the American Psychological Association (APA, 2018) and Masten (2016), resilience is not a singular trait that is either present or absent within an individual. The capacity to be resilient is also dependent on many systems. Some of these systems can be out of the individual's locus of control (Masten, 2016). These researchers also believe that resilience involves thoughts and behaviors, leading to perseverance that can be learned and developed. Given that student resilience is not an immovable trait; rather, it is a modifiable construct, by using these experiences/learned behaviors as efficacious opportunities for growth, Eells (2017) and Leppin et al. (2014) believe that future adversities can be more manageable for students in higher education.

Southwick, Bonanno, Masten, Panter-Brick, and Yehuda (2014) take a more philosophical view of resilience adding that it is not just about functioning well in light of less than positive circumstances. It is the individual's ability to make sense of the moral aspects of his or her life and determining what matters most at a given time. These researchers add that "the goal may not be to agree on one definition of resilience, but rather to carefully define various types of resilience depending on the context" (Southwick, et al., 2014, p. 11).

\subsection{Factors Influencing Student Resilience}

Throughout the literature, the importance of a growth mindset has been stressed as a factor that impacts resilience (Dweck, 2007; Eells, 2017; Wilson, 2016). 
A growth mindset versus a fixed mindset is attitudinal in nature and is essential to resilience. Individuals who have fixed mindsets are characterized by defining "smart" as completing a task perfectly, making no mistakes, finishing the task quickly and perceiving all tasks as easy. These individuals feel that the potential to achieve is innate. On the other hand, individuals who possess a growth mindset realize that potential is developed over time. They view challenges as chances to learn and grow. They view being smart as improving from where one started (Dweck, 2007; Wilson, 2016). Resilient individuals are also proactive in their problem-solving approaches, possessing the ability to interpret their experiences in positive and constructive ways (Huang \& Lin, 2013). Related to a growth mindset is the phenomenon of grit. Duckworth, Peterson, Matthews, and Kelly (2007) studied grit during the same timeframe as Dweck's work on growth mindset was published. These authors define grit as "passion and perseverance toward personal goals that is maintained in spite of setbacks and little success in the short-term" (p. 1087). In their review of Duckworth and colleagues' work, Gray and Mannahan (2017) posited that there is debate that grit may be a better predictor of achievement than IQ, referring to grit as a "non-cognitive supplemental predictor of academic success" (p. 17).

Related to growth mindset is the concept of learned optimism (Seligman, 1990). This author describes three components that make up learned optimism: 1) permanence; 2) pervasiveness; and 3) personalization. Resilient people are able to see the impermanence of negative events and understand that the positive events that happen in life are related to ongoing strengths that can be developed. With regard to pervasiveness, resilient people do not view failure in one area as failure in life as a whole. Finally, people who are optimistic are able to see negative events in a logical context, realizing that factors that influence the negative event are out of their control.

The individual characteristics or capacities noted in the preceding paragraphs are viewed in the literature as protective factors (Petrowski, Brähler, \& Zenger, 2014).Brzycki and Brzycki (2016); Dyrbye, et al. (2010);Eells (2017); Lynch (1977); Masten and Reed (2002); and Mathad, Pradhan, and Riesh (2017) point out that there are additional protective factors that resilient individuals possess. These include self-knowledge, active coping (including emotional acceptance), sense of meaning and gratitude, close relationships (i.e., interpersonal sensitivity), empathy, humor, and spirituality.

Elaborating on the aforementioned protective factors, Eells (2017) stresses that it is possible to be aware of, accepting and embracing of what is happening in one's life without trying to change things. In order to abandon strategies when giving up is what is called for in the presence of larger goals calls for mindfulness. In their research, Mathad, Pradhan, and Riesh (2017) found that resilience is positively correlated with mindfulness. Because resilience is considered as a measure of stress coping ability, resilience and mindfulness play an important part in fighting stress. Mindfulness through meditation is one way to develop active coping and emotional acceptance (Eells, 2017).Bryant and Veroff (2007) indicate that mindfulness should not be targeted toward coping with negative experiences. Mindfulness in the form of "savoring" (or the active process of enjoyment) are the capacities individuals have to attend to, appreciate, and enhance the positive experiences in their lives.

Because human beings are social creatures by nature, social connections are one of the most important protective factors possessed by resilient individuals (Eells, 2017). Isolation from others can be toxic, not just symbolically, but also physiologically, negatively impacting the body's nervous system as well as other systems of the body. Physical closeness has had the following physiological effects in individuals: an increase in oxygen flow, a reduction in blood pressure, and a release of oxytocin, which dampens the stress response by inhibiting the amygdale (Lynch, 1977). Eells (2017) stresses that it is this research that supports the need for methods and/or programs that facilitate social connectedness among students in institutions of higher education. This will be discussed in a later section in more depth.

Another important factor that influences resilience is vulnerability. Directly opposite of protective factors, vulnerability factors can have detrimental effects when individuals are in high-risk situations, according to Kitano and Lewis (2005). These authors explain this construct in terms of the vulnerability a student has in a high-risk environment if s/he has no successful experience in dealing with hardship. This can be exemplified by graduate students who have always been successful academically throughout grades K through 12 and perhaps even in their baccalaureate program. Their first "taste" of less than optimum performance comes when they begin graduate school. They have not had ample experience in dealing with lower grades and as a result, do not know how to cope with perceived poor performance.

According to Alvarado, Spatariu, and Woodbury (2017) as well as Armstrong, Galligan and Critchley (2011), emotional intelligence may also be directly connected to resilience. That is, these two variables influence one another. These authors note that students who possess high emotional intelligence evidence adaptive behaviors during stressful situations. Students with high emotional intelligence are effectively able to use positive emotions to their advantage (Tugade \& Frederickson, 2002). Brzycki and Brzycki (2016) believe that emotional intelligence is important to develop through college experiences. 
Up to now, institutions of higher learning have not fully addressed this critical dimension of the self and of learning. These authors posit that colleges and universities need to provide strategies to develop emotional IQ, self-awareness and health through student success programs.

\subsection{Lack of Resilience in Students}

Dan Jones, the Director of the Counseling Center at Appalachian State University, indicates that students today appear less resilient than in the past. "They haven't developed skills in how to sooth themselves, because their parents have solved all their problems and removed the obstacles." He adds, "They don't seem to have as much gut as previous generations" (Wilson, 2015, para. 19).Some refer to the aforementioned style of parenting and "over-involvement" as helicopter parenting. While this is not the sole reason for lack of resilience in students who are in higher education, it should certainly be considered as a contributing factor. In their research looking at the effect of helicopter parenting on students in higher education, Ulutas and Aksoy (2014) add that students in higher education who are raised by overinvolved parents do not develop important competencies such as time management and coping skills.

Another factor contributing to lack of resilience is cognitive dissonance. Dissonance occurs when a student believes something about him/herself and then do or experience something that is against that understanding (Brzycki \& Brzycki, 2016). For example, high performing students who suddenly find themselves struggling academically could result in cognitive dissonance. Often students who enter graduate studies have been successful throughout their entire K-12 career and even during their baccalaureate program. School seemed to "come easy" to them and there was not a high need for studying or managing one's time in the same way they would have to for graduate studies.

\section{Theoretical Underpinnings for Resilience}

Given that resilience and student success have a strong relationship (Bondy, Ross, Gallingane, \& Hambacher, 2007) it is difficult to discuss theoretical bases of student resilience without discussing what the theoretical foundations of student success are. As with resilience, the concept of student success is also multi-faceted. Strange (2010) indicates that there is a large body of research that has reshaped how institutions of higher learning design and promote the concept of student success. There is now greater attention given to student learning as well as assessing student learning within academic programs (i.e., assessment plans).As far back as the early 1920s, researchers have understood the importance of the learning environment to student success. Dewey (1922) stated, "Whether we permit chance environments to do the work, or whether we design environments for the purpose makes a great difference" ( $p$. 22).Strange and Banning's (2015) campus environment theory supports Dewey's (1922) work. Their theory posits that student success in higher education occurs though intentional design of the environment. That environment shapes and influences student behavior, and subsequently, student learning. According to these authors, there are a number of items in terms of the campus environment that can make a living-learning community effective and impact student success. These include universal design, learning communities, multicultural environments, online environments, social networking, and safety.

With regard to addressing student resilience and its theoretical base, one of the overarching themes in the literature is that of self-efficacy, or one's belief in one's ability to succeed in specific situations or accomplish a task (Bandura, 1982). Students who have a strong sense of self-belief are motivated to perform well even in the face of challenging situations including those life changes that college brings (Darling, McWey, Howard, \& Olmstead, 2007; Martin, 2002). Martin's (2002) research discusses need achievement and self-worth motivation theories which describe student characteristics in terms of three different typologies: success-oriented, failure-avoidant, and failure-accepting. There is clear evidence of self-control and high self-belief in the success-oriented student. In her research, Carlson (2001) found that self-control behaviors such as class attendance and number of hours spent studying were positively correlated with high resilience. Success-oriented students also made good use of classroom tools that were provided. In the failureavoidant student there is anxiety and low risk-taking to the point of not attempting tasks at all. Finally, the failureaccepting student evidences self-sabotage. Like the failure-avoidant student, the failure-accepting student lacks motivation as well as resilience. Parr, Montgomery, and DeBell (1998) suggest using Mihaly Csikszentmihalyi's Flow Theory to build student resilience in the field of counseling. A state of "flow" will yield the following characteristics: positive emotions, higher level of concentration, intrinsic motivation, and a sense of satisfaction. Resilience from the perspective of the Flow Theory develops around a complex self. The self gains resilience from a proactive perspective that sees challenge in adversity. As a result, the self extracts meaning and purpose from chaos. When students establish clear goals, are centered, have choices, are committed to tasks, and are able to stretch themselves toward increasing levels of differentiation and integration, the aforementioned authors believe that higher student resilience will result. In her review of the literature on student resilience in higher education, Carlson (2001) found as one of the overarching themes the concept of social support. Social connectedness and integration theories have been widely used in the public health arena (Pound \& Campbell, 2015). 
Social support is not only beneficial, it is essential. Brzycki and Brzycki (2016) contend that by interacting with others, students in higher education can build resilience. Carlson (2001) notes that social support can come from a variety of sources including parents, mentors, clergy, coaches, instructors, and sometimes even peers.

\section{Methods of Addressing Student Resilience in Higher Education}

In consideration of the various methods in use to address student resilience in higher education, some key principles are addressed. These include considering students' needs, differentiating support(s) (including creative mentoring models), being flexible in approaches, responding to students in a timely manner, being proactive rather than reactive to students' needs, applying resources efficiently and sustainably, focusing on outcomes and results and ensuring that services are planned and implemented collaboratively (Strange \& Cox, 2010). Kuh, Kinzie, Schuh, and Whitt (2005) investigated what high performing colleges do to promote student success and found that in a number of instances, fostering student agency (student involvement) in a variety of ways was effective. Examples of student agency include but are not limited to requiring student participation and leadership and employing student workers who provide a range of student services.

Simple practices of reminding students to practice gratitude and providing students strategies for building a "positive spirit" and mindfulness were reported by Bryant and Veroff (2007) and Wilson (2016) to increase their resilience. This resilience came in the form of their ability to focus and help them to feel motivated to learn more challenging concepts and material as well as to have specific processes for deriving joy in their lives. This is similar to Wong's (1993) resource-congruence model for stress management that stresses positive beliefs and optimism. Positive attitude and values also play a part in Eells' (2017) resilience model, represented by the acronym SAVES. The components of Eells' model include: Social connection, Attitude, Values, Emotional acceptance, and Silliness/humor.Connecting students to one another also plays a key role in addressing student resilience. This is typically seen more at the undergraduate level in colleges and universities rather than at the graduate level. However, this does not mean that graduate-level students would not derive benefit from systems and programs that include student bonding activities. Kuh et al. (2005) found that when students experience a feeling of belonging, they are better able to connect with their peers. This connection is associated with persistence as well as satisfaction. This is consistent with the work of Edwards, Catling, and Parry (2016), who stressed the importance of relationships with peers in higher education as an intervention for building resilience.

In what is considered a high impact model to address student success in higher education, Brzycki et al. (2016) developed the $i$ Self Model. This model focuses on addressing students as whole persons. Students have four broad entry points for intervention: 1) well-being (e.g., purpose in life, self-knowledge, emotional IQ, and physical and psychological health); 2) self-determination (e.g., motivation, self-efficacy, and belonging); 3) cognitive processing (e.g., achievement, information processing, and metacognition); and 4) unique potential (e.g., self-esteem, identity, and self-efficacy). These authors noted the importance of the final entry point of unique potential, which includes learning more about oneself. In fact, this is "the most important factor in creating a happy, healthy, flourishing life, and therefore, a better world" (p. 29). It is only when higher education can support students in gaining self-knowledge for personal and professional potential that these learners can then demonstrate real competencies and ultimately lead successful lives after graduating. There is research to show that resilience training programs have merit. Leppin et al. (2014) conducted a random effects meta-analysis across thirteen contributing trials. Their findings discovered "an overall benefit of generalized stress-directed resiliency training in improving resilience in individuals within three months of follow up" (p. 11). Dweck (2019) notes that when larger scale, lengthy interventions are implemented, there can be difficulty in determining effect size and it can also be expensive to replicate and sustain over time. New advances in self-administered resilience interventions are being developed and may be an answer to the aforementioned drawbacks to larger scale programs.

\section{Conclusion}

This literature review has looked at how various researchers and scholars define resilience as well as considering those factors that influence resilience and sharing what the literature has to say about why there is a lack of student resilience. Theoretical bases for resilience models were also included as it is important that interventions that are put into place have a strong theoretical foundation. Finally, methods addressing student resilience that are currently in place in institutions of higher learning were explored. It is a combination of all of the above that will assist researchers to develop future resilience programs that will effectively and efficaciously address the needs of students in postbaccalaureate programs of study. 


\section{References}

Alvarado, A., Spatariu, A., \& Woodbury, C. (2017). Resilience and emotional intelligence between first generation college students and non-first generation college students. Focus on Colleges, Universities \& Schools, 11(1), $1-10$.

American Psychological Association.(2018).The road to resilience [Brochure]. Retrieved from http://www.apa.org/helpcenter/road-resilience.aspx

Armstrong, A. R., Galligan, R. F., \& Critchley, C. R. (2011). Emotional intelligence and psychological resilience to negative life events. Personality and Individual Differences, 51(3), 331-336. doi: 10.1016/j.paid.201.03.025

Avey, J. B., Luthans, F., \& Jensen, S. M. (2009). Psychological capital: A positive resource forcombating employee stress and turnover. Human Resource Management, 48(5), 677-693.

Bandura, A. (1982). Self-efficacy mechanism in human agency. American Psychologist, 37(2), 122-147.

Beiter, R., Nash, R., McCrady, M., Rhodes, M., Linscomb, M., Clarahan, M., Sammut, S. (2015). The prevalence and correlates of depression, anxiety, and stress in a sample of college students. Journal of Affective Disorders, 173, 90-96.

Bondy, E., Ross, D. D., Gallingane, C., \& Hambacher, E. (2007). Creating environments of success and resilience: Culturally responsive classroom management and more. Urban Education, 42(4), 326-348.

Bryant, F. B., \& Veroff, J. (2007). Savoring: A new model of positive experience. Mahwah, NJ: Lawrence Erlbaum Associates, Inc.

Brzycki, E. J., \& Brzycki, H. G. (2016). Student success in higher education: Developing the whole person through high impact practices. State College, PA: BG Publishing.

Carver, C. S. (1998). Resilience and thriving: Issues, models, and linkages. Journal of Social Issues, 54(2), 245-266.

Connor, K. M., \& Davidson, J. R. T. (2003). Development of a new resilience scale: The Connor-Davidson Resilience Scale (CD-RISC). Depression and Anxiety, 18(2), 76-82.

Darling, C. A., McWey, L. M., Howard, S. N., \& Olmstead, S. B. (2007). College student stress: The influence of interpersonal relationships on sense of coherence. Stress \& Health, 23, 215-229.

De Oliveria, A. P., Machado, A. G., \& Aranha, R. N. (2017). Identification of factors associated with resilience in medical students through a cross-sectional census. BMJOpen, 7(11), 1-8. doi: 10.1136/bmjopen-2017-017189

Dewey, J. (1922). Democracy and education: An introduction to the philosophy of education. New York, NY: The McMillan Company.

Duckworth, A. L., Peterson, C., Matthews, M. D., \& Kelly, D. R. (2007). Grit: Perseverance and passion for long-term goals. Journal of Personality and Social Psychology, 92(6), 1087-1101.

Dweck, C. S. (2019). The choice to make a difference. Perspectives on Psychological Science, 14(1), 21-25.

Dweck, C. S. (2007). Mindset: The new psychology of success. New York, NY: Ballantine Books.

Dyrbye L. N., Power, D. V., Massie, F. S., Eacker, A., Harper, W., Thomas, M. R.,... Shanafelt, T. D. (2010). Factors associated with resilience to and recovery from burnout: A prospective, multi-institutional study of US medical students. Medical Education, 44, 1016-26.

Edwards, T., Catling, J. C., \& Parry, E. (2016). Identifying predictors of resilience in students. Psychology Teaching Review, 22(1), 26-34.

Eells, G. T. (2017). Hyper-achievement, perfection, and college student resilience. Journal of College and Character, 18(2), 77-82. doi: 10.1080/2194587X.2017.1300096

First, J., First, N.L., \& Houston, J.B. (2018). Resilience and coping intervention (RCI): A group intervention to foster college student resilience. Social Work with Groups, 41(3), 198-210.

Gray, J. P., \& Mannahan, K. K. (2017). How well do trait measures of achievement predict students' perceptions of the link between personal effort and academic performance? The Journal of Effective Teaching, 17(1), 16-27.

Kegan, J. (1994). In over our heads: The mental demands of modern life. Cambridge, MA: Harvard University Press.

Kitano, M. K., \& Lewis, R. B. (2005). Resilience and coping: Implications for gifted children and youth at risk. Roeper Review, 27(4), 200-215.

Kuh, G. D., Kinzie, J., Schuh, J. H., \& Whitt, E. J. (2005). Student success in college: Creating conditions that matter. San Francisco, CA: Jossey-Bass.

Leppin, A. L., Bora, P. R., Tilburt, J. C., Gionfriddo, M. R., Zeballos-Palacios, C., et al. (2014). The efficacy of resiliency training programs: A systematic review and meta-analysis of randomized trials. PLoS ONE 9(10), 115. doi:10.1371/journal.pone.0111420

Luthar, S. S. (2006). Resilience in development: A synthesis of research across five decades. In D. Cichetti \&D. Cohen (Eds.), Developmental psychopathology volume 3: Risk disorder and adaptation (2nd ed., pp. 696-739). Hoboken, NJ: John Wiley \& Sons. 
Lynch, J. (1977). The broken heart: The medical consequences of loneliness. New York, NY: Basic Books.

Martin, A. (2002). Motivation and academic resilience: Developing a model for student enhancement. Australian Journal of Education, 46(1), 34-49.

Masten, A. S. (2016). Resilience in developing systems: The promise of integrated approaches. European Journal of Developmental Psychology, 13(3), 297-312.

Masten, A.S., \& Reed, M.G.J. (2002). Resilience in development. In C.R. Snyder \& S.J. Lopez (Eds.), Handbook of positive psychology (pp. 74-88). New York: Oxford University Press.

Mathad, M. D., Pradhan, B., \& Riesh, S. K. (2017). Correlates and predictors of resilience among baccalaureate nursing students. Journal of Clinical and Diagnostic Research, 11(2), 5-8. doi: 10.7860/JCDR/2017/24442

McCann, C.M., Beddoe, E., McCormick, K., Huggard, P., Kedge, S., Adamson, C., \& Huggard, J. (2013). Resilience in the health professions: A review of recent literature. International Journal of Wellbeing, 3(1), 60-81. doi: 10.5502/ijw.v3i1.4

Mohapel, P. (2012). The Quick Emotional Intelligence Self-Assessment. Retrieved from http://www.dreanthonyallen.com/newsite/wpcontent/uploads/2012/08/emotional-intelligence-selfassessment.pdf

Morales, E. E. (2008). Exceptional female students of color: Academic resilience and gender in higher education. Innovative Higher Education, 33, 197-213.

Parr, G. D., Montgomery, M., \& DeBell, C. (1998). Flow theory as a model for enhancing student resilience. Professional School Counseling, 1(5), 26-31.

Prihadi, K., Cheow, D. Y., Yong, J. E., \& Sundrasagran, M. (2018). Improving resilience and self-esteem among university students with entrepreneurship stimulation board game. International Journal of Evaluation and Research in Education, 7(1), 48-56.

Pound, P., \& Campbell, R. (2015). Locating and applying sociological theories of risk-taking to develop public health interventions for adolescents. Health Sociology Review, 24(1), 64-80.

Seligman, M. E. P. (1990). Learned optimism. New York, NY: Simon \& Schuster, Inc.

Southwick, S. M., Bonanno, G. A., Masten, A. S., Panter-Brick, C., \& Yehuda, R. (2014). Resilience definitions, theory, and challenges: Interdisciplinary perspectives. European Journal of Psychotraumatology, 5(1), 25338. Retrieved from https://www.ncbi.nlm.nih.gov/pmc/articles/PMC4185134/pdf/EJPT-5-25338.pdf

Strange, C. C., \& Banning, J. H. (2015). Designing for learning: Creating campus environments for student success $\left(2^{\text {nd }}\right.$ edition). San Francisco, CA: Jossey-Bass Publishers.

Strange, C. C., \& Cox, D. H. (2010). Principles and strategies of good practice in student services. In D. H. Cox \& C. C. Strange (Eds.), Achieving student success: Effective student services in Canadian higher education (237245). Montreal, QC: McGill-Queens University Press.

Tugade, M. M., \& Fredrickson, B. L. (2002). Positive emotions and emotional intelligence. In L.Feldman Barrett \& P. Salovey (Eds.), The wisdom of feeling(pp. 319-340). New York,NY: Guilford.

Ulutas, I., \& Aksoy, A. B. (2014, January). The impact of helicopter parenting on the social connectedness and anxiety level of university students. Paper presented at the International Academic Conference on Social Sciences and Humanities, Prague.

Wilson, J. T. (2016). Brightening the mind: The impact of practicing gratitude on focus and resilience in learning. Journal of the Scholarship of Teaching and Learning, 16(4), 1-13. doi: 10.14434/josotl.v16i4.19998

Windle, G. (2011). What is resilience? A review and concept analysis. Reviews in Clinical Gerontology, 21, 152-169.

Winfield, L. (1994). Developing resilience in urban youth. (Evaluative feasibility report No.: ED3788289. North Central Regional Educational Lab. Retrieved from ERIC database.

Wong, P. T. (1993). Effective management of lifestress: The resource-congruence model. StressMedicine, 9, 51-60. http://dx.doi.org/10.1002/smi.2460090110 